Noriaki Kanaya MD, Masayasu Nakayama MD, Satoshi Fujita MD PhD, Akiyoshi Namiki MD PhD

\title{
Haemodynamic and EEG changes during rapid-sequence induction of anaesthesia
}

\begin{abstract}
The relationship between the changes in haemodynamic function and the electroencephalogram (EEG) during rapidsequence induction of anaesthesia was studied in $15 \mathrm{ASAI}$ patients. Anaesthesia was induced with a bolus thiamylal (5 $\mathrm{mg} \cdot \mathrm{kg}^{-1}$ iv) followed by succinylcholine $\left(1 \mathrm{mg} \cdot \mathrm{kg}^{-1}\right)$. Tracheal intubation was attempted one minute after the injection of succinylcholine. The EEG was monitored by a computerized aperiodic analysis device, the Lifescan (10) (Neurometrics $(1)$, San Diego, $C A$ ) using the activity edge $(A E)$ to detect brain electrical activity. Afier induction of anaesthesia, systolic blood pressure (SBP) decreased by $11 \%$ from the baseline value, and the $A E$ decreased from $13.0 \mathrm{~Hz}$ to $3.4 \mathrm{~Hz}$. Following tracheal intubation, the $s B P$ increased from the post-induction values by $44 \%(P<0.05)$, and the $A E$ increased to $13.1 \mathrm{~Hz}(P<0.05)$ simultaneously. In conclusion, rapid-sequence induction using thiamylal (5 $\left.\mathrm{mg} \cdot \mathrm{kg}^{-1}\right)$ caused depression in brain activity as assessed by $A E$, while laryngoscopy and tracheal intubation caused an increase in activity. This indicates that this dose of thiamylal for rapid-sequence induction may not be sufficient to sustain an adequate anaesthetic level and blunt the haemodynamic responses to intubation.
\end{abstract}

Cette travail évalue chez 15 patients ASA I le rapport entre les changements hémodynamiques et l'électroencéphalogramme (EEG) pendant linduction de l'anesthésie à séquence rapide. L'anesthésie est induite avec un bolus de thiamylal (5 $\mathrm{mg} \cdot \mathrm{kg}^{-1}$ iv) suivi par de la succinylcholine $\left(1 \mathrm{mg} \cdot \mathrm{kg}^{-1}\right)$. Lintubation

\section{Key words}

BRAIN: electroencephalogram;

ANAESTHESIA TECHNIQUE: rapid sequence induction

From the Department of Anesthesiology, School of Medicine, Sapporo Medical University, S-1, W-16, Chuo-ku, Sapporo, Japan 060.

Address correspondence to: Dr. Kanaya, Department of Anesthesiology, School of Medicine, Sapporo Medical University, S-1, W-16, Chuo-ku, Sapporo, Japan 060.

Presented at the 67th Congress of the International Anesthesia Research Society, San Diego, California, March 1993.

Accepted for publication 20th April, 1994. endotrachéale est effectuée une minute après linjection de la succinylcholine. L'EEG est monitoré par un module d'analyse apériodique informatisé, Lifescan ${ }^{(10)}$ (Neurometrics $\left.{ }^{(10}\right)$ San Diego, $C A$ ) utilisant l'activité de pourtour (edge activité $=E A$ ) pour révéler l'activité électrique cérébrale. Après l'induction de l'anesthésie, la pression artérielle systolique (PAs) sabaisse de $11 \%$ sa valeur initiale et l'EA diminue de $13 \mathrm{~Hz}$ à $3,4 \mathrm{~Hz}$. Après l'intubation trachéale, la PAs augmente de $44 \%$ au dessus de la valeurs post-induction $(P<0,05)$ et en même temps I'AE augmente à $13,1 \mathrm{~Hz}(P<0,05)$. En conclusion, l'induction séquentielle rapide avec le thyamilal $\left(5 \mathrm{mg} \cdot \mathrm{kg}^{-1}\right)$ produit une dépression de l'activité cérébrale révélée par l'EA, alors que la laryngoscopie et lintubation augmente cette activité. Ceci montre qu'avec une induction à séquence rapide cette dose de thiamylal pourrait être insuffisante pour l'obtention d'un niveau d'anesthésie adéquat et l'abolition des réponses hémodynamiques de l'intubation.

Rapid-sequence induction of anaesthesia is now frequently used for emergency patients. Various sequences have proved effective, but all tend to cause broad haemodynamic fluctuations. ${ }^{1}$ These responses sometimes lead to fatal damages in patients with hypertension, ischaemic heart disease, intracranial aneurysm, or increased intracranial pressure. Many studies have used the electroencephalogram (EEG) in an attempt to measure the effect of anaesthesia on the cerebral cortex. However, to the authors' knowledge, there have been no simultaneous investigations of the EEG and haemodynamic responses during rapid-sequence induction of anaesthesia. Recently, on-line computerized aperiodic analysis of the EEG was used to assess the depth of anaesthesia in highdose fentanyl anaesthesia. ${ }^{2}$ The purpose of this study was to determine whether one of these devices, the Lifescan (1) EEG Monitor (Neurometrics (i), San Diego, CA) provides useful additional information about cerebral responses during rapid-sequence induction.

\section{Methods}

After Institutional Human Investigation Committee approval and with informed consent, EEG monitoring 
was performed in 15 adult patients (ASA I) undergoing elective surgery. None of the patients had neurological deficits or cardiovascular disease. No sedative drugs were given preoperatively.

The Lifescan ${ }^{(10}$ monitor uses aperiodic analysis, which maps each waveform for its frequency, amplitude and time course. The EEG signal is divided into five components $(0.5-3,3-7,7-9,9-12$ and $12-30 \mathrm{~Hz})$ and displayed in five colours on a high-resolution colour monitor. Slow waves are identified by the presence of zerocrossings between high peaks and low valleys, while fast waves are identified simply by consecutive peaks and valleys. The Lifescan (ii) uses a variable called the "activity edge" (AE) to simplify identification of trends in brain electrical activity. The AE is the average of the observed frequencies weighted by amplitude over the previous two seconds. When AE is set at $80 \%$, it means that $80 \%$ of the whole electrical brain activity exists within the amplitude.

The EEG was recorded continuously from the waking state using a Lifescan 10 . The AE was set at $80 \%$ and the upper limit of the amplitude was set at $400 \mu \mathrm{V}$. The EEG was taken using five electrodes bilaterally in a frontal-ipsilateral mastoid configuration. After five minutes preoxygenation, anaesthesia was induced with thiamylal $5 \mathrm{mg} \cdot \mathrm{kg}^{-1}$ followed by succinylcholine 1 $\mathrm{mg} \cdot \mathrm{kg}^{-1} \dot{i}$. The lungs were not ventilated during induction. One minute after succinylcholine, tracheal intubation was attempted. Cases of failed tracheal intubation (laryngoscopy $>30 \mathrm{sec}$ ) were not included in the study. After intubation, anaesthesia was maintained with oxygen-nitrous oxide-isoflurane (1.2\%) or -sevoflurane (1.7\%). Systolic blood pressure (sBP), heart rate (HR) and $\mathrm{AE}$ for each hemisphere were recorded at the following times: (1) awake; (2) immediately before laryngoscopy and intubation; and (3) one minute after intubation. The rate pressure product (RPP) was calculated from HR and sBP. Data (mean \pm SEM) were analyzed by Student's $t$ test for paired samples. A $P$ value $<0.05$ was considered significant.

\section{Results}

The changes in $\mathrm{SBP}$ and HR are shown in Figure 1. Systolic blood pressure decreased by $11.4 \%$ from the baseline value after induction of anaesthesia (pre-int), and increased by $43.9 \%$ after tracheal intubation (post-int) from pre-int. The HR increased by $11.2 \%$ and $9.1 \%$ after pre-int and post-int, respectively, in comparison with their previous values $(P<0.05)$. After tracheal intubation, the RPP increased by $54.6 \%$ compared with baseline value (data are not shown). After the injection of thiamylal ( $5 \mathrm{mg} \cdot \mathrm{kg}^{-1}$ ), the AE showed a rapid transition 'to a slow wave and then remained constant. It returned

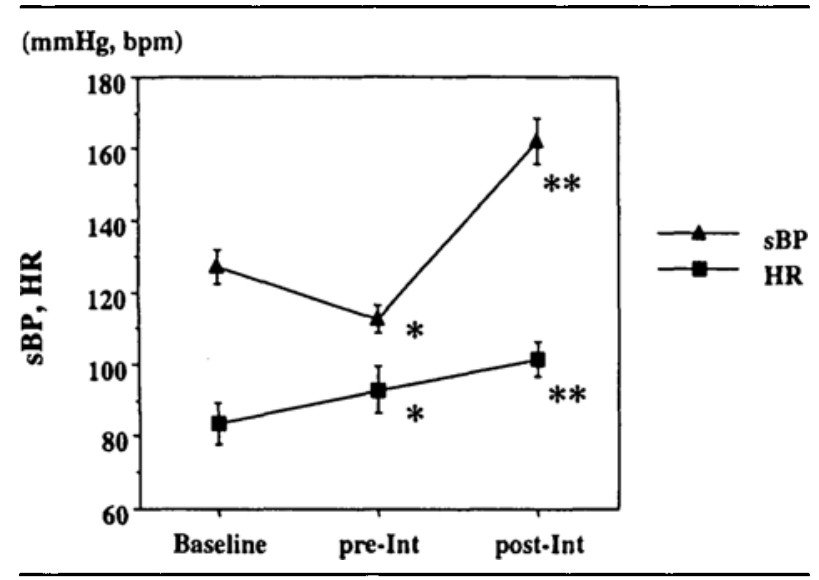

FIGURE 1 Changes of systolic blood pressure (sBP) and heart rate (HR) after thiamylal (pre-int) and tracheal intubation (post-int). Values are mean \pm SEM. ${ }^{*} P<0.05$ vs. baseline value. ${ }^{* *} P<0.05$ vs baseline and pre-int.

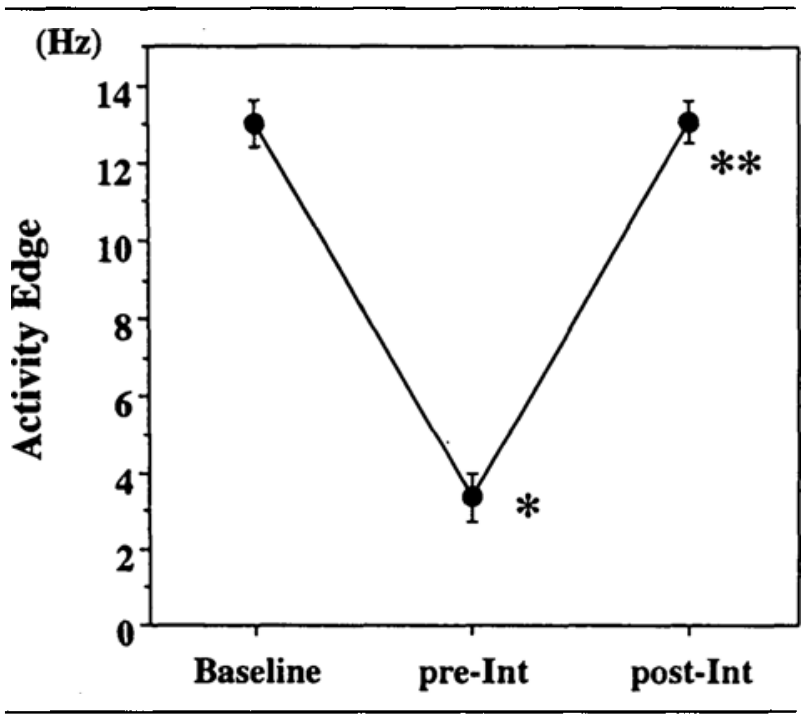

FIGURE 2 Change of the activity edge after thiamylal (pre-int) and endotracheal intubation (post-int). Values are mean \pm SEM $* P<0.05$ vs baseline value. $* * P<0.05$ vs pre-int.

quickly to about the same level as the original concurrent with tracheal intubation (Figure 2). The mean value of AE before induction was $13.0 \pm 2.2 \mathrm{~Hz}$, and it decreased to $3.4 \pm 2.2 \mathrm{~Hz}$ after induction $(P<0.05)$. After tracheal intubation, the $\mathrm{AE}$ increased to $13.1 \pm 1.9 \mathrm{~Hz}(P<$ $0.05)$.

\section{Discussion}

The stress response to laryngoscopy is well known to be a centrally mediated sympathetic reflex, ${ }^{3-5}$ but little is now known about the mechanisms of the haemodynamic and cerebral responses to laryngoscopy and tracheal intubation. Finfer et al. ${ }^{6}$ presumed that stretching 
of the pharyngeal and laryngeal tissues during laryngoscopy was the major cause of the haemodynamic response. Another investigation concluded that stimulation of the supraglottic region by tissue tension during larygnoscopy was the major cause of the haemodynamic and catecholamine responses and that tracheal intubation contributed very little additional stimulation. ${ }^{5}$ In contrast, Hassan et al. ${ }^{7}$ reported that orotracheal intubation was associated with further increments of plasma epinephrine concentrations. In the present study, it was shown that thiamylal $\left(5 \mathrm{mg} \cdot \mathrm{kg}^{-1}, i v\right)$ caused cerebral and haemodynamic depression, while cerebral activity and haemodynamic variables were increased after tracheal intubation. We suggest that the haemodynamic responses to laryngoscopy and tracheal intubation may reflect the cerebral activation during rapid-sequence induction in our present study.

The electroencephalogram (EEG) has proved invaluable in some medical fields as it reflects changes in cerebral physiology, is continuous and non-invasive, and changes consistently with administration of anaesthetic drugs. However, some studies have concluded that the EEG is not a reliable index of the depth of anaesthesia ${ }^{8-10}$ for two reasons. First, there is no "gold standard" for assessing the clinical depth of anaesthesia let alone an electroencephalographic standard. Different kinds of anaesthetics produce different EEG patterns; the difference between the EEG effects of barbiturates and opioids are a well-known example. Low concentrations of thiopentone first produce EEG activation and then EEG slowing. Ultimately a burst suppression pattern and an isoelectric EEG occur." In contrast, fentanyl does not cause activation, but rather, progressive slowing finally to slow delta waves. There is a ceiling in the EEG slowing produced by fentanyl. ${ }^{12}$ Because the combination of these anaesthetics can cause considerable confusion for understanding the EEG changes, we induced anaesthesia by thiamylal alone.

Second, there have been no adequate methods of measuring the EEG instead of the 16-lead EEG. Monitors that process the EEG signal have been developed to simplify recognition and interpretation of EEG changes. However, these monitors are usable only with certain anaesthetics which produce changes amenable to mathematical analysis. The Fast Fourier transformation (FFT) provides effective and practical waveform analysis for fentanyl anaesthesia because an isoelectric EEG does not occur with opioids; but the method is not useful with thiopentone. ${ }^{12}$ However, Bührer et al. ${ }^{13}$ suggested aperiodic waveform analysis for processing of the isoelectric EEG occurring from thiopentone. Therefore, we adopted the aperiodic analysis to estimate thiamylal's effect on the EEG.

In our present study, plasma concentrations of thiam- ylal were not measured. Hudson et al. ${ }^{11}$ demonstrated that the thiopentone serum concentration correlated well with its effect on the "spectral edge," an index generated by one kind of FFT, in an analysis of EEGs from healthy volunteers. In their study, the spectral edge shifted to a lower frequency with increasing thiopentone concentrations. It took at least ten minutes for the spectral edge to return to baseline after discontinuation of thiopentone. They also noted hysteresis between the change in plasma concentration and change in spectral edge when the drug was administered rapidly. In our study, tracheal intubation was performed at least within two minutes after the injection of thiamylal. Therefore, it is presumed that the increase of $\mathrm{AE}$ after intubation was not due to a decrease in plasma thiamylal concentration.

Some investigators have described the effect of noxious stimuli on the brain. Peripheral noxious stimuli reach the brain via afferent systems that pass through the ascending reticular activating systems of the brain stem. These systems regulate corticocerebral function and thus may affect the EEG pattern. Miyauchi et al. ${ }^{14}$ reported that the depth of anaesthesia affects the brain response to supramaximal stimulation of the sciatic nerve in dogs. Although stimulation caused EEG activation and increased cerebral oxygen requirement and blood flow under light levels of thiopentone anaesthesia, the same stimulation produced no change in these variables under deep levels of thiopentone anaesthesia. In our study, the usual induction dose of thiamylal did not limit the AE and haemodynamic changes following tracheal intubation. This indicates that $5 \mathrm{mg} \cdot \mathrm{kg}^{-1}$ thiamylal may not be sufficient to prevent activation of the brain resulting from noxious stimuli. Further examination of the doseresponse relationship between thiamylal and EEG change is necessary.

In humans, Rampil and Matteo ${ }^{15}$ examined the haemodynamic responses and the EEG spectral edge frequency (SEF) during laryngoscopy and tracheal intubation. They administered a bolus of thiopentone (3-5 $\left.\mathrm{mg} \cdot \mathrm{kg}^{-1} \dot{i}\right)$, followed by succinylcholine $\left(1.5 \mathrm{mg} \cdot \mathrm{kg}^{-1}\right.$ $i v)$ and lidocaine (75-100 $\mathrm{mg} i v$ ). Fentanyl and droperidol were administered randomly prior to induction. They concluded that SEF $<14 \mathrm{~Hz}$ before induction predicted a smaller haemodynamic response following stimulation. The effect of thiopentone on SEF was not clear in their experiment because various drugs (especially opioids) were administered simultaneously during the induction.

In conclusion, rapid-sequence induction using thiamylal (5 $\mathrm{mg} \cdot \mathrm{kg}^{-1}$ ) caused depression in brain activity as assessed by AE, while laryngoscopy and tracheal intubation caused an increase in activity. This indicates that this induction dose of thiamylal is not sufficient to prevent the haemodynamic response to tracheal intubation. 


\section{References}

1 Stoelting RK, Peterson C. Circulatory changes during anesthetic induction: impact of $d$-tubocurarine pretreatment, thiamylal, succinylcholine, laryngoscopy, and tracheal lidocaine. Anesth Analg 1976, 55: 77-81.

2 Ghignone M, Quintin L, Duke PC, Kehler CH, Calvillo $O$. Effects of clonidine on narcotic requirements and hemodynamic response during induction of fentanyl anesthesia and endotracheal intubation. Anesthesiology 1986; 64: 36-42.

3 Russell WJ, Morris RG, Frewin DB, Drew SE. Changes in plasma catecholamine concentrations during endotracheal intubation. Br J Anaesth 1981; 53: 837-9.

4 Derbyshire $D R$, Smith $G$, Achola $K J$. Effect of topical lignocaine on the sympathoadrenal responses to tracheal intubation. Br J Anaesth 1987; 59: 300-4.

5 Shribman AJ, Smith G, Achola AJ. Cardiovascular and catecholamine responses to laryngoscopy with or without tracheal intubation. Br J Anaesth 1987; 59: 295-9.

6 Finfer SR, MacKenzie SIP, Saddler JM, Watkins TGL. Cardiovascular responses to tracheal intubation: a comparison of direct laryngoscopy and fibreoptic intubation. Anaesth Intensive Care 1989; 17: 44-8.

7 Hassan HG, El-Sharkawy TY, Renck H, Mansour G, Fouda $A$. Hemodynamic and catecholamine responses to laryngoscopy with vs. without endotracheal intubation. Acta Anaesthesiol Scand 1991; 35: 442-7.

8 Galla SJ, Rocco AG, Vandam LD. Evaluation of the traditional signs and stages of anesthesia: an electroencephalographic and clinical study. Anesthesiology 1958; 19: 328-38.

9 Levy WJ. Intraoperative EEG patterns: implications for EEG monitoring. Anesthesiology 1984; 60: 430-4.

10 Berezowskyj JL, McEwan JA, Anderson GB, Jenkins LC. A study of anaesthesia depth by power spectral analysis of the electroencephalogram (EEG). Can Anaesth Soc J 1976; 23: 1-8.

11 Hudson RJ, Stanski DR, Saidman LJ, Meathe E. A model for studying depth of anesthesia and acute tolerance to thiopental. Anesthesiology 1983; 59: 301-8.

12 Scott JC, Ponganis KV, Stanski DR. EEG quantitation of narcotic effect: the comparative pharmacodynamics of fentanyl and alfentanil. Anesthesiology 1985; 62: 234-41.

13 Bührer M, Maitre PO, Hung OR, Ebling WF, Shafer $S L$, Stanski $D R$. Thiopenal pharmacodynamics: I. Defining the pseudo-steady-state serum concentration-EEG effect relationship. Anesthesiology 1992; 77: 226-36.

14 Miyauchi Y, Sakabe T, Maekawa T, Ishikawa T, Takeshita $H$. Responses of EEG, cerebral oxygen consumption and blood flow to peripheral nerve stimulation during thiopentone anaesthesia in the dog. Can Anaesth Soc J 1985; 32: 491-8.

15 Rampil IJ, Matteo RS. Changes in EEG spectral edge fre- quency correlate with the hemodynamic response to laryngoscopy and intubation. Anesthesiology 1987; 67: 139-42. 